\title{
Psychometric performance of the brazilian version of the Mini- cuestionario de calidad de vida en la hipertensión arterial (MINICHAL) ${ }^{1}$
}

\author{
Ana Lúcia Soares Soutello² \\ Roberta Cunha Matheus Rodrigues ${ }^{3}$ \\ Fernanda Freire Jannuzzi ${ }^{4}$ \\ Thaís Moreira Spana ${ }^{4}$ \\ Maria Cecilia Bueno Jayme Gallani ${ }^{5}$ \\ Wilson Nadruz Junior ${ }^{6}$
}

\begin{abstract}
This study aimed to evaluate the feasibility, acceptability, ceiling and floor effects, reliability, and convergent construct validity of the Brazilian version of the Mini Cuestionario de Calidad de Vida en la Hipertensión Arterial (MINICHAL). The study included 200 hypertensive outpatients in a university hospital and a primary healthcare unit. The MINICHAL was applied in $3.0( \pm 1.0)$ minutes with $100 \%$ of the items answered. A "ceiling effect" was observed in both dimensions and in the total score, as well as evidence of measurement stability (ICC=0.74). The convergent validity was confirmed by significant positive correlations between similar dimensions of the MINICHAL and the SF-36, and significant negative correlations with the Minnesota Living with Heart Failure Questionnaire - MLHFQ, however, correlations between dissimilar constructs were also observed. It was concluded that the Brazilian version of the MINICHAL presents evidence of reliability and validity when applied to hypertensive outpatients.
\end{abstract}

Descriptors: Quality of Life; Questionnaires; Hypertension; Psychometrics; Validation Studies; Nursing.

\footnotetext{
${ }^{1}$ Supported by Fundo de Apoio ao Ensino, à Pesquisa e à Extensão (FAEPEX), Campinas, SP, Brazil, Process \# 52899-10.

${ }^{2}$ RN, M.Sc. in Nursing. E-mail: asoutello@yahoo.com.br.

${ }^{3}$ RN, Ph.D. in Nursing, Associate Professor, Departamento de Enfermagem, Faculdade de Ciências Médicas, Universidade Estadual de Campinas, SP, Brazil. E-mail: robertar@fcm.unicamp.br.

${ }^{4}$ RN, Doctoral Student, Faculdade de Ciências Médicas, Universidade Estadual de Campinas, SP, Brazil. E-mail: Fernanda fernandafj@yahoo.com.br, Thaís - thaisms@gmail.com.

${ }^{5}$ RN, Ph.D. in Nursing, Associate Professor, Faculdade de Ciências Médicas, Universidade Estadual de Campinas, Brazil. Professor, Faculté des Sciences Infirmières, Université Laval, Québec, QC, Canada. E-mail: ceciliag@fcm.unicamp.br.

${ }^{6}$ Physician, Cardiologist, Professor, Faculdade de Ciências Médicas, Universidade Estadual de Campinas, SP, Brazil. E-mail: wilnj@fcm.unicamp.br.
}

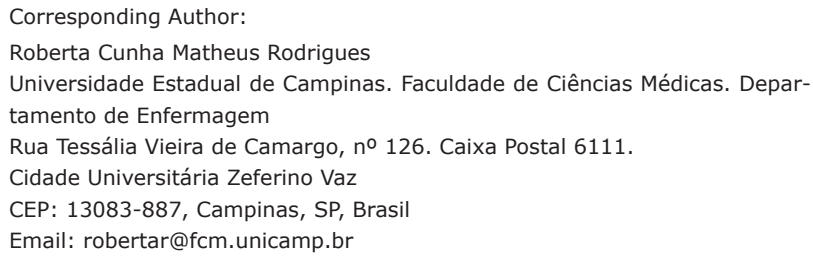




\title{
Desempenho psicométrico da versão brasileira do Mini-cuestionario de calidad de vida en la hipertensión arterial (MINICHAL)
}

Este estudo teve como objetivo avaliar a praticabilidade, a aceitabilidade, os efeitos teto e chão, a confiabilidade e a validade de constructo convergente da versão brasileira do mini - cuestionario de calidad de vida en la hipertensión arterial - Minichal. Participaram do estudo 200 pacientes hipertensos, em seguimento ambulatorial, em hospital universitário e unidade básica de saúde. O Minichal foi aplicado em 3,0 $( \pm 1,0)$ minutos, com 100\% dos itens respondidos. Foi observado efeito teto em ambas as dimensões e escore total, bem como evidências de estabilidade da medida ( $\mathrm{ICC}=0,74$ ). A validade convergente foi confirmada por correlações significativas positivas entre dimensões similares do Minichal e do SF-36, e por correlações significativas negativas com o Minnesota Living with Heart Failure Questionnaire - MLHFQ, embora correlações entre constructos dissimilares tenham sido observadas. Conclui-se que a versão brasileira do Minichal apresenta evidência de confiabilidade e validade, quando aplicada em hipertensos, em seguimento ambulatorial.

Descritores: Qualidade de Vida; Questionários; Hipertensão; Psicometria; Estudos de Validação; Enfermagem.

\section{Desempeño psicométrico de la versión brasileña del Minicuestionario de calidad de vida en la hipertensión arterial (MINICHAL)}

\begin{abstract}
Este estudio tuvo como objetivo evaluar la practicidad, la aceptabilidad, los efectos techo y suelo, la confiabilidad y la validez de constructo convergente de la versión brasileña del Minicuestionario de Calidad de Vida de la Hipertensión Arterial - MINICHAL. Participaron del estudio 200 pacientes hipertensos en seguimiento en ambulatorio, en hospital universitario y en Unidad Básica de Salud. El MINICHAL fue aplicado en 3,0 $( \pm 1,0)$ minutos, con $100 \%$ de los ítems respondidos. Fue observado "efecto techo" en ambas dimensiones y puntaje total, así como evidencias de estabilidad de la medida $(\mathrm{CCI}=0,74)$. La validez convergente fue confirmada por correlaciones significativas positivas entre dimensiones similares del MINICHAL y del SF-36, y por correlaciones significativas negativas con el Minnesota Living with Heart Failure Questionnaire - MLHFQ, a pesar de que correlaciones entre constructos no similares hubiesen sido observadas. Se concluye que la versión brasileña del MINICHAL presenta evidencia de confiabilidad y validez cuando aplicada en hipertensos en seguimiento en ambulatorio.
\end{abstract}

Descriptores: Cuestionarios de Calidad de Vida; Hipertensión; Psicometría; Estudios de Validación; Enfermería.

\section{Introduction}

Hypertension, considered a major risk factor for cardiovascular disease ${ }^{(1)}$, affects about one billion people worldwide(2). In Brazil, population-based surveys conducted in Southeastern and Southern cities showed a prevalence of between $22.3 \%$ and $43.9 \%$ of hypertensive individuals ${ }^{(3)}$. Besides the recognition and control of hypertension and its effects on morbidity and mortality, the evaluation of the health related quality of life (HRQOL) has been considered another important measure of outcome in treating hypertensive patients $^{(4)}$. Studies have reported worse HRQoL among hypertensive individuals compared with those without hypertension(5), which has been attributed to factors such as adverse effects related to the pharmacological therapy ${ }^{(6)}$, stigma associated with recognition by the subject of the hypertension - called the labeling

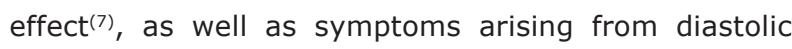
heart failure ${ }^{(8)}$. 
The literature reports few specific instruments for evaluating HRQoL in hypertensive individuals, highlighting the Questionnaire for the Assessment of Quality of Life of Bulpitt and Fletcher( ${ }^{(9)}$, the Arterial Hypertension Quality of Life Questionnaire - the Calidad de Vida en la Hipertensión Arterial - CHAL, developed in Spain(10) and its abbreviated version - the MiniCuestionario de Calidad de Vida en la Hipertensión Arterial - MINICHAL ${ }^{(11)}$, and the Hyper 31, a self-applied instrument developed in Italy(12). Of these, the Bulpitt and Fletcher questionnaire ${ }^{(13)}$ and MINICHAL ${ }^{(14)}$ have been adapted to the Portuguese language of Brazil. While the Bulpitt and Fletcher questionnaire ${ }^{(9)}$ evaluates the physical well-being (symptoms), psychological wellbeing and especially the perception of the effects of pharmacological treatment in the lifestyle of hypertensive outpatients $^{(9)}$, the MINICHAL aims to evaluate the involvement of the somatic and mental dimensions of the health of hypertensive patients, without giving importance to the perception of the impact of the pharmacological treatment in the life of the subject.

In the study of adaptation of the MINICHAL for the Brazilian culture some aspects of reliability and validity of the Brazilian version were analyzed, with an analysis of its internal consistency and its factors to evaluate its construct validity as well as the evaluation of the capacity of the MINICHAL in discriminating between HRQoL of hypertensive and normotensive individuals ${ }^{(14)}$, for analysis of its criterion validity. The properties evaluated in the study of adaptation although important, were not exhaustive. When using an instrument in the clinical practice or in research it is very important to have the most comprehensive information possible about its psychometric performance, its strength and limitations, for the correct interpretation of the results obtained with the measurement. Thus, this study proposes to amplify the evaluation of the psychometric properties of the Brazilian version of the MINICHAL with regard to measurement stability and convergent construct validity. It is hoped that the results of this study will contribute to the refinement of the specified questionnaire to measure HRQOL in hypertension, aiming to its future use in evaluating the impact of nursing interventions on the HRQoL of hypertensive outpatients.

\section{Aim}

This study aimed to evaluate the feasibility, acceptability, ceiling and floor effects, temporal stability and the convergent construct validity of the Brazilian version of the Mini-Cuestionario de Calidad de Vida en la Hipertensión Arterial - MINICHAL when applied in hypertensive outpatients, in a University Hospital and a Primary Health Unit

\section{Methods}

\section{Study site}

The research was conducted at the Hypertension Outpatient Clinic of a large university hospital and in a Primary Health Unit, both in the State of São Paulo.

\section{Subjects}

The subjects of this study were 200 hypertensive outpatients aged over 18 years followed in the referred services for more than six months. Patients with secondary hypertension, co-morbidities that impacted on the HRQoL (Terminal Chronic Renal Disease and Neoplasia) and chronic pneumopathy not related to hypertension (in order to exclude patients with dyspnea unrelated to hypertension), as well as those that presented an inability to comprehend and communicate verbally were excluded. The sample size was estimated by the difference between the means in the domains of the MINICHAL, obtained from the pilot study analysis $(n=32)$. Considering $a=0.05$ and $\beta=0.20$, a minimum sample of 200 subjects was estimated.

\section{Data Collection}

Data collection was conducted from May to December 2009. Data were collected through individual interviews, according to the following steps:

- First Step: the registration of available charge information was used to obtain the sociodemographic and clinical data of the subjects, followed by a structured interview to obtain sociodemographic and clinical data not available in the hospital records, as well as for the measurement of HRQoL;

- Second Step: seven days after the first application, the MINICHAL was applied again (re-test) in a proportion of the subjects $(n=60)$ who participated in the first application (test).

To collect data relative to the HRQoL, the Brazilian versions of the Medical Outcomes Study 36-Item ShortForm Health Survey - SF-36, of the Minnesota Living with Heart Failure Questionnaire - MLHFQ and the MINICHAL were used. It is noteworthy that all the instruments were administered through an interview, due to the low education level of the subjects enrolled (mean of 6 and median of 4 years of schooling). 
Medical Outcomes Study 36-Item Short-Form Health Survey (SF-36)

This is a generic questionnaire developed to measure HRQoL, self-administered, multidimensional and adapted to the Brazilian culture by Ciconelli in 1999(15). It comprises 36 items grouped into eight domains or components: Physical functioning (10 items), Rolephysical (four items), Pain (two items), General Health Perception (five items), Vitality (four items), Social Functioning, (two items), Role-Emotional (three items), Mental Health (five items) and one Health Transition item comparing current health condition to health condition 1 year earlier. Each dimension is individually analyzed, and scores on the eight components may range from 0 to 100 , with higher scores indicating better health status.

Minnesota Living with Heart Failure Questionnaire MLHFQ

The Brazilian version of the MLHFQ, adapted for the Brazilian culture by Carrara(16) was used. The MLHFQ was developed by Rector et al., in 1987(17) in order to evaluate the HRQoL of patients suffering from heart failure, considering the self-assessment of the patient regarding the impact of the disease and of its treatment. It is composed of 21 items that refer to the limitations associated with heart failure, which impeach the patient from living as he would like in the last month. The 21 items are distributed in the dimensions - Physical and Emotional and in a set of non-grouped responses, which are involved only in the total score. A value from 0 (zero) to 5 (five) can be assigned for each item, where zero corresponds to the best and five to the worst HRQoL. The total score is obtained by the sum of the 21 items, ranging from zero to $105^{(17)}$. Although constructed for evaluating the HRQoL in patients with heart failure, the items of the MLHFQ are based on the perception of the symptoms, especially fatigue and dyspnea, which allows its use with hypertensive patients.

Mini-Cuestionario de Calidad de Vida en la Hipertensión Arterial - MINICHAL

A version adapted to the Portuguese of $\mathrm{Brazi}^{(14)}$ was used, which is the shortened version ${ }^{(18)}$ of the Calidad de Vida en la Hipertensión Arterial - CHAL, developed (10) and validated in Spain ${ }^{(11)}$. It is a self-administered instrument consisting of 16 items divided into two dimensions: State of Mind, composed of 10 items (questions 1 to 10 ) and Somatic Manifestations, which includes six items (questions 11 to 16), and a general QoL question which does not appear in either of the dimensions and is used to evaluate the responsiveness of the instrument, with four possible answers on a Likert-type scale of four points: 0 (No, not at all), 1 (Yes, a little), 2 (Yes, quite a lot), and 3 (Yes, very much). The answer to each of the items refers to the last seven days. The total score is obtained from the sum of all items and ranges from zero (best health level) to 48 (worst health level)(18). It is noteworthy that in the validation study of the MINICHAL for the Brazilian culture, item 10 was excluded from the dimension State of Mind and included in the dimension Somatic Manifestations, and the question referring to the general perception of the health of the patient was included as a $17^{\text {th }}$ question ${ }^{(14)}$. In the present study the composition of the dimensions and respective scores established in the creation of MINICHAL ${ }^{(18)}$ were considered.

\section{Data Analysis}

The data obtained from the application of the instruments were transported to the program Excel for Windows/2003 and then to the program SAS (Statistical Analysis System) for Windows, version 9.02, for the current analysis:

Ceiling and floor effects, feasibility and acceptability

The percentage of patients who scored at floor level (equivalent to the worse $10 \%$ of the results of the scale, i.e. score $\geq 27$ for the State of Mind dimension, $\geq 16.2$ for the Somatic Manifestations dimension and $\geq 43.2$ for the total score) or ceiling level (equivalent to the best possible $10 \%$ of the results of the scale, i.e. score $\leq 3$ for the Mental State dimension, $\leq 1.8$ for the Somatic Manifestations dimension and $\leq 4.8$ for the total score $)^{(19)}$ were evaluated. Ceiling and floor effects were considered substantial if greater than $25 \%{ }^{(20)}$.

The feasibility of the MINICHAL was evaluated from the time spent on the application of the instrument. The viability/acceptability was evaluated from the percentage of unanswered items and from the proportion of patients that did not respond to all the items ${ }^{(21)}$.

\section{Reliability}

The reliability was evaluated with regard to the measurement stability, i.e. the concordance between repeated measurements (test-retest), through the Intraclass correlation coefficient (ICC). An ICC $>0.70$ was considered as evidence of measurement stability ${ }^{(22)}$. 


\section{Construct validity}

The convergent construct validity was assessed using the Spearman correlation coefficient between the scores of the Brazilian versions of the MINICHAL, the MLHFQ and the SF-36. Correlation coefficients $<0.30$ were considered of low magnitude, between 0.30 and 0.50 of moderate magnitude, and $>0.50$ of strong magnitude, as recommended by Ajzen and Fishbein(23). Based on a previous study ${ }^{(24)}$, negative significant correlations of high magnitude $(>0.50)$ between the dimensions and the total score of the MINICHAL and the conceptually similar domains of the SF-36 (in the evaluation of the scores of the MINICHAL, the higher the score, the better the HRQoL) and significant positive correlations of high magnitude between the dimensions of the MINICHAL and similar dimensions of the MLHFQ were hypothesized. Correlations of moderate to low magnitude were hypothesized between conceptually divergent dimensions. The findings were considered significant when the $p$-value $\leq 0.05$.

\section{Ethical considerations}

The study was approved by the local ethics committee (Protocol no. 1083/2008). The researcher explained the purpose of the study to the eligible patients and invited them to participate. The usual guarantees of confidentiality were given and written informed consent was obtained from all patients.

\section{Results}

\section{Sociodemographic and clinical data}

The sample $(n=200)$ was composed mostly of women $(58.0 \%)$ with mean age of $57( \pm 11.3)$ years, Caucasian $(64.5 \%)$, married $(61.5 \%)$, with a mean of $6( \pm 4.1)$ years of study, active $(59.0 \%)$, with individual and family income means of $1.6( \pm 1.5)$ and $3.2( \pm 2.1)$ minimal wages, respectively. The sociodemographic and clinical characteristics of the subjects studied are presented in Table 1.

Table 1 - Sociodemographic and clinical characteristics of hypertensive patients $(n=200)$ in outpatient at the university hospital and the Primary Health Unit. Campinas, SP, Brazil, 2010

\begin{tabular}{|c|c|c|c|c|c|}
\hline Sociodemographic Variables & $\mathbf{n}$ & $\%$ & Mean (sd) & Median & Variation \\
\hline Age (years) & & & $57(11.3)$ & 57 & $21-82$ \\
\hline \multicolumn{6}{|l|}{ Gender } \\
\hline Female & 116 & 58 & & & \\
\hline \multicolumn{6}{|l|}{ Race $(n=198)$} \\
\hline Caucasian & 129 & 64.5 & & & \\
\hline Schooling (years) & & & $6(4.1)$ & 4 & $0-16$ \\
\hline \multicolumn{6}{|l|}{ Marital Status } \\
\hline Married & 123 & 61.5 & & & \\
\hline Separated/Divorced/Cohabiting & 28 & 14 & & & \\
\hline Widowed & 27 & 13.5 & & & \\
\hline Single & 22 & 11 & & & \\
\hline \multicolumn{6}{|l|}{ Employment status ( $n=198)$} \\
\hline Retired & 81 & 40.5 & & & \\
\hline Working & 76 & 38.0 & & & \\
\hline Housework & 42 & 21.0 & & & \\
\hline \multicolumn{6}{|l|}{ Income } \\
\hline Individual monthly income $\left(\mathrm{MW}^{*}\right)(\mathrm{n}=199)$ & & & $1.6(1.5)$ & 1.29 & $0,0-8,6$ \\
\hline Family monthly income $\left(\mathrm{MW}^{*}\right)(\mathrm{n}=197)$ & & & $3.2(2.1)$ & 2.58 & $0,0-12,9$ \\
\hline \multicolumn{6}{|l|}{ Clinical variables } \\
\hline Length of hypertension (years) & & & $12.6(10.5)$ & 10 & $1-53$ \\
\hline \multicolumn{6}{|l|}{ Risk Factors and/or Associated Clinical Conditions } \\
\hline Dyslipidemia & 133 & 66.5 & & & \\
\hline Abdominal obesity ${ }^{\dagger}$ & 132 & 66.0 & & & \\
\hline Family history of $C V D \ddagger$ & 117 & 58.5 & & & \\
\hline Obesity (Body Mass Index $>30$ ) & 90 & 45.0 & & & \\
\hline Metabolic Syndrome & 82 & 41.0 & & & \\
\hline Glucose intolerance $\S$ & 55 & 27.5 & & & \\
\hline Hyperuricemia $\|$ & 31 & 15.5 & & & \\
\hline Smoker (current) & 21 & 10.5 & & & \\
\hline
\end{tabular}


Table 1 - (continuation)

\begin{tabular}{|c|c|c|c|c|c|}
\hline Sociodemographic Variables & $\mathbf{n}$ & $\%$ & Mean (sd) & Median & Variation \\
\hline Number of co-morbidities & & & $3.1(1.7)$ & 3 & $0-7$ \\
\hline \multicolumn{6}{|l|}{$C V D \neq$} \\
\hline Left ventricular hypertrophy ** & 85 & 42.5 & & & \\
\hline Coronary heart disease and/or myocardial revascularization & 26 & 13.0 & & & \\
\hline Heart Failure & 12 & 6.0 & & & \\
\hline Stroke & 9 & 4.5 & & & \\
\hline Carotid intimal-medial thickness ${ }^{+\dagger}$ and/or transient cerebral ischemia & 7 & 3.5 & & & \\
\hline Peripheral arteriopathy & 6 & 3.0 & & & \\
\hline \multicolumn{6}{|l|}{ Symptoms } \\
\hline Headache & 94 & 47.0 & & & \\
\hline Edema & 87 & 43.5 & & & \\
\hline Arrhythmia & 71 & 35.5 & & & \\
\hline Lipothymia & 57 & 28.5 & & & \\
\hline Dyspnea & 57 & 28.5 & & & \\
\hline Angina & 54 & 27.0 & & & \\
\hline Number of associated symptoms & & & $2.1(1.6)$ & 2 & $0-6$ \\
\hline Number of medications in use & & & $3.6(2.4)$ & 3 & $0-11$ \\
\hline
\end{tabular}

$* \mathrm{MW}=$ minimum wage. One (1) minimum wage $=\mathrm{R} \$ 465.00$, value of the minimum wage in the period of data collection; ${ }^{+} \mathrm{WC}>102 \mathrm{~cm}$ for men and $>88$ $\mathrm{cm}$ for women, ${ }^{\ddagger}$ CVD: Cardiovascular Disease; ${ }^{\S}$ glycemia between $102-125 \mathrm{mg} / \mathrm{dl}$; " uric acid $>7 \mathrm{mg} / \mathrm{dl}$ for men and $>6.5 \mathrm{mg} / \mathrm{dl}$ for women; $* * \mathrm{LVH} \geq 125 \mathrm{~g} /$ $\mathrm{m}^{2}$ for men and $\geq 110 \mathrm{~g} / \mathrm{m}^{2}$ for women) $;{ }^{+1}$ intima-media thickness $>0.9 \mathrm{~mm}$

The group studied was characterized by the mean length of $12.6( \pm 10.5)$ years of hypertension history, with 3.09 ( \pm 1.7$)$ associated clinical conditions, especially dyslipidemia (66.5\%), abdominal obesity (66.0\%) and family history of CVD (58.5\%). Only $13.0 \%$ of the sample reported coronariopathy and/or myocardial revascularization. A mean of $2.1( \pm 1.6)$ associated symptoms was obtained, with reports of headache $(47.0 \%)$ and edema (43.5\%) being more frequent.

\section{Feasibility, acceptability, ceiling and floor effects and descriptive measures of HRQoL}

The mean length of application of the MINICHAL was $3.01( \pm 1.05)$ minutes, ranging from 1.1 to 8.1 minutes with a median of 2.5 minutes. All patients answered $100 \%$ of the items of the MINICHAL in the first application. The measurements of HRQoL obtained from the application of the generic instrument (SF-36) and the specific instruments (MLHFQ and MINICHAL), as well as the results of the evaluation of the ceiling and floor effects are presented in Table 2.

Table 2 - Descriptive measurements of the SF-36, MLHFQ and the Brazilian version of the MINICHAL and floor and ceiling effects $(n=200)$. Campinas, SP, Brazil, 2010.

\begin{tabular}{|c|c|c|c|c|c|c|}
\hline Measures of HRQoL & Mean (sd) & Median & Observed range & Possible range & Floor effect (\%) & Ceiling effect (\%) \\
\hline \multicolumn{7}{|l|}{ SF-36 } \\
\hline Physical functioning & $65.2(26.7)$ & 65.0 & $0-100$ & $0-100$ & 3.5 & 29 \\
\hline Role-physical & $57.8(39)$ & 75.0 & $0-100$ & $0-100$ & 19.5 & 35.5 \\
\hline Pain & $56.5(27.1)$ & 57.5 & $0-100$ & $0-100$ & 5 & 16.5 \\
\hline General Health Perception & $63.5(24)$ & 67.0 & $0-100$ & $0-100$ & 2.5 & 18 \\
\hline Vitality & $61.3(23.0)$ & 65.0 & $5-100$ & $0-100$ & 2 & 15 \\
\hline Social functioning & $70.6(27.5)$ & 75.0 & $0-100$ & $0-100$ & 2 & 32 \\
\hline Role-emotional & $57.5(39.6)$ & 66.7 & $0-100$ & $0-100$ & 22.5 & 37.5 \\
\hline Mental Health & $64.2(25.3)$ & 68.0 & $4-100$ & $0-100$ & 1.5 & 20.5 \\
\hline \multicolumn{7}{|l|}{ MLHFQ } \\
\hline MLHFQ - Physical & $8.9(8.2)$ & 7.0 & $0-29$ & $0-40$ & - & 42 \\
\hline MLHFQ - Emotional & $5.8(5.4)$ & 4.0 & $0-25$ & $0-25$ & 1 & 34.5 \\
\hline MLHFQ - Total & $21.5(17.7)$ & 16.0 & $0-72$ & $0-105$ & - & 32.5 \\
\hline \multicolumn{7}{|l|}{ MINICHAL } \\
\hline Mental State & $6.7(5.4)$ & 5.0 & $0-30$ & $0-30$ & 1 & 31.5 \\
\hline Somatic Manifestations & $3.4(2.6)$ & 3.0 & $0-12$ & $0-18$ & - & 25.5 \\
\hline Total Score & $10.2(7.0)$ & 8.0 & $0-37$ & $0-48$ & - & 22.5 \\
\hline
\end{tabular}


Analysis of the distribution of the scores of the MINICHAL in the study population revealed the occurrence of a moderate ceiling effect in the MINICHAL total $(22.5 \%)$ and substantial ceiling effect in the Mental State (31.5\%) and Somatic Manifestations (25.5\%) dimensions. No floor effect was observed.

\section{Reliability - measurement stability}

The measurement stability was assessed using the Intra-class Correlation Coefficient (ICC) in patients undergoing the re-test $(n=60)$. The analysis indicated an ICC $=0.74$ for the total score, 0.78 for the Mental Status dimension, and 0.64 for the Somatic Manifestations dimension.

\section{Construct validity}

The construct validity of the Brazilian version of the MINICHAL was demonstrated by the correlation between the scores of the MINICHAL and the generic (SF-36) and specific (MLHFQ) HRQoL measurements. Correlations between the similar dimensions of the MINICHAL and the dimensions of the SF-36 and MLHFQ are presented in Table 3.

Table 3 - Spearman's correlation coefficients of the Brazilian MINICHAL domains with SF-36 and MLHFQ dimensions $(n=200)$. Campinas, SP, Brasil, 2010

\begin{tabular}{|c|c|c|c|c|}
\hline \multirow{2}{*}{ HRQoL instruments } & \multicolumn{4}{|c|}{ MINICHAL } \\
\hline & Somatic manifestations & Mental state & Item 17 & Total score \\
\hline \multicolumn{5}{|l|}{ SF-36 } \\
\hline Physical functioning & $-0.51^{*}$ & $-0.42^{*}$ & $-0.30^{*}$ & $-0.52^{*}$ \\
\hline Role-physical & $-0.42^{*}$ & $-0.47^{*}$ & $-0.31^{*}$ & $-0.52^{*}$ \\
\hline Pain & $-0.46^{*}$ & $-0.41^{*}$ & $-0.19^{\dagger}$ & $-0.49^{*}$ \\
\hline General Health Perceptions & $-0.38^{*}$ & $-0.51^{*}$ & $-0.35^{*}$ & $-0.53^{*}$ \\
\hline Vitality & $-0.45^{*}$ & $-0.61^{*}$ & $-0.31^{*}$ & $-0.63^{*}$ \\
\hline Social functioning & $-0.26^{*}$ & $-0.52^{*}$ & $-0.22^{*}$ & $-0.47^{\dagger}$ \\
\hline Role-emotional & $-0.34^{*}$ & $-0.48^{*}$ & $-0.29^{*}$ & $-0.49^{*}$ \\
\hline Mental Health & $-0.40^{*}$ & $-0.62^{*}$ & $-0.33^{*}$ & $-0.62^{*}$ \\
\hline \multicolumn{5}{|l|}{ MLHFQ } \\
\hline MLHFQ - Physical & $0.60^{*}$ & $0.64^{*}$ & $0.40^{*}$ & $0.73^{*}$ \\
\hline MLHFQ - Emotional & $0.42^{*}$ & $0.60^{*}$ & $0.33^{*}$ & $0.62^{*}$ \\
\hline MLHFQ - Total & $0.58^{*}$ & $0.68^{*}$ & $0.43^{*}$ & $0.75^{*}$ \\
\hline
\end{tabular}

${ }^{*} \mathrm{p}<0.001 ;{ }^{\dagger} \mathrm{p}<0.01$

As previously hypothesized, strong magnitude correlations were observed between the MINICHALtotal and all dimensions/domains of the MLHFQ and SF-36, except for the Pain ( $r=-0.49)$, Social functioning $(r=-0.47)$ and Role-emotional $(r=-0.49)$ domains of the SF-36, where the correlations were of moderate magnitude. The State of Mind dimension of the MINICHAL was strongly correlated with the Vitality ( $r=-$ $0.61)$ and General Health Perception ( $r=-0.51)$ domains of the SF-36, whereas moderate magnitude correlations were observed between the Somatic Manifestations dimension of the MINICHAL and the Vitality $(r=-0.45)$ and General Health Perception $(r=-0.38)$ domains of the SF-36.

Considering the analysis between similar dimensions, strong magnitude correlations were found between the dimension Somatic Manifestations of the MINICHAL, the physical dimension of the MLHFQ $(r=0.60)$ and the Physical functioning domain of the SF-36 ( $r=-0.60)$, as previously hypothesized. Moderate magnitude correlations were found between the Somatic Manifestations dimension of the MINICHAL and the Role-physical $(r=-0.42)$ and Pain $(r=-0.36)$ domains of the SF-36. The State of Mind dimension of the MINICHAL presented strong magnitude correlations with the Emotional dimension of the MLHFQ and the Mental Health $(r=0.62)$ and Social functioning $(r=0.52)$ domains of the SF-36 and a moderate magnitude correlation with the Role-emotional domain of the SF$36(r=0.48)$.

However, when considering the relationship between dissimilar constructs, a strong correlation was observed between the State of Mind dimension of the Brazilian version of the MINICHAL and the Physical dimension of the MLHFQ $(r=0.64)$. 


\section{Discussion}

The findings of this study indicate evidence of feasibility and viability/acceptability of the Brazilian version of the MINICHAL, characterized by the low onus on the respondent, i.e. the mean application time of $3.0( \pm 1.0)$ minutes, with $100 \%$ of items answered in the first application. In the original study of the MINICHAL (18), in which the instrument was completed by the respondent, the mean application time was 7.2 (6.5) minutes and $5.7 \%$ of the patients did not answer all items. The analysis of the distribution of the scores of the Brazilian version of the MINICHAL in the study population revealed a moderate ceiling effect in the MINICHAL total $(22.5 \%)$ and a substantial ceiling effect in the State of Mind (31.5\%) and Somatic Manifestations (25.5\%) dimensions, as well as an absence of floor effect. The ceiling effect occurs when the distribution of the scores is asymmetric and a certain percentage of the population score at the higher level of the measure, which prevents the detection of changes in health status in situations of health improvement in the population evaluated. The floor effect manifests itself when a percentage of subjects score in the lower level of the measure, which prevents detection by the instrument of changes regarding situations of worsening health of the studied population(19). The occurrence of these effects may indicate impairment of psychometric properties, such as sensitivity - the ability of the instrument to measure any change in health status, regardless of its magnitude, and responsiveness - the ability of the instrument to measure the magnitude of health status change in the study population ${ }^{(25)}$. It was therefore observed that the Brazilian version of the MINICHAL can be potentially sensitive and responsive to the measurement of worsening, since the floor effect was rarely observed, but may have a reduced potential for measuring improvement, since the presence was verified of a substantial ceiling effect in both dimensions and a moderate effect in the total score. The analysis pointed to the satisfactory reproducibility of the Brazilian version of the MINICHAL, with similar ICC values found in the Spanish validation study of the MINICHAL $($ ICC $=0.70$ in the State of Mind dimension, and 0.68 in the Somatic Manifestations dimension)(18).

In the present study evidence was observed of convergent validity of the MINICHAL, since moderate to strong magnitude correlations were found between similar domains. Correlations of moderate magnitude found between the State of Mind dimension of the
MINICHAL and the Role-emotional domain of the SF-36 and between the Somatic Manifestations dimension of the MINICHAL and Role-physical and Pain domains of the SF-36, can be explained by the fact that the items comprising the physical dimension of the SF-36 and of the MINICHAL are distinct. It was observed that the items that comprise the Role-physical domain of the SF-36 are intended to evaluate the perception of the limitations due to the presence of symptoms, and the items that comprise the Somatic Manifestations dimension of the MINICHAL evaluate the perception of the symptoms related to hypertension without, however, evaluating the perception of limitation imposed by the symptom on the performance of daily living activities. Likewise, items that constitute the Role-Emotional domain of the SF-36 refer to the limitations imposed by the emotional aspects, while the State of Mind dimension of the MINICHAL refers to the perception of signs/symptoms by the subject, regardless of their impact on the performance of daily living activities. However, correlations between dissimilar domains were observed, particularly between the State of Mind dimension of the MINICHAL and the Physical dimension of the MLHFQ.

A previous study ${ }^{(26)}$, which tested the convergent validity of the Brazilian version of the MINICHAL through correlation with a generic HRQoL measure, also found a strong magnitude correlation $(r=0.53)$ between the State of Mind domain of the MINICHAL and the Physical dimension of the generic measure of HRQoL, although in this study the composition of factors suggested in the adaptation study of the MINICHAL for the Brazilian culture was used, in which item 10 is considered in the composition of the State of Mind dimension. Thus, one possible explanation for these findings may be related to the factorial composition of the original MINICHAL with the allocation of items in the State of Mind dimension, where the interpretation may suggest disease repercussions in the somatic dimension and not in the emotional dimension, as previously hypothesized. Therefore, item 9 of the MINICHAL - Do you feel worn out and without energy? - may have been interpreted by the subjects, as the presence of "weakness" and "fatigue" symptoms often mentioned by hypertensive patients and thus, with repercussions in the physical dimension of the HRQoL. Similarly, item 10 of the MINICHAL - have you felt sick? - may have been interpreted as a physical or emotional repercussion of the disease in the life of the subject. Additionally, the impact of the disease in the life of the subject assessed by item 7 - "Making your relationships or activities with family members and 
friends difficult" that constitutes the physical dimension of the MLHFQ approaches the repercussions evaluated by items 2 and 3 ("Have you had difficulty maintaining your normal social relationships?" and "Have you had difficulty in relating to people?", respectively), which constitute the State of Mind dimension of the Brazilian version of the MINICHAL, which could explain the magnitude of the correlation found between the State of Mind dimension of the MINICHAL and the Physical dimension of the MLHFQ. Thus, the results regarding the convergent validity of the MINICHAL through correlation with measures of general and specific HRQoL indicate the need for further studies to confirm the structure of factors proposed by the original model of the MINICHAL, as well as to confirm the proposed factorial composition proposed for the Brazilian version of the questionnaire.

\section{Conclusion}

The Brazilian version of the MINICHAL showed evidence of feasibility, acceptability and potential sensitivity for detection of worsening of HRQoL evidenced by the lack of floor effect; however, the finding of substantial ceiling effects in both dimensions and a moderate effect in the total score indicates potential limitations in the detection of improvements in HRQoL. The convergent validity was partially supported, since a strong magnitude correlation was detected between similar constructs, but also between dissimilar ones. It is recommended that further studies are carried out in order to confirm the structure of factors of the Brazilian version of the MINICHAL and its convergent validity, as well as to investigate its sensitivity and responsiveness.

\section{References}

1. Chobanian AV. Improved hypertension Control: cause for some celebration. JAMA. 2010; 303(20):2082-3.

2. Chobanian AV, Bakris GL, Black HR, Cushman WC, Green LA, Izzo JL, et al. The seventh report of the Joint National Committee on Prevention, Detection, Evaluation, and Treatment of high blood pressure. The JNC 7 Report. JAMA. 2003;289(19):2560-72.

3. Sociedade Brasileira de Cardiologia; Sociedade Brasileira de Hipertensão; Sociedade Brasileira de Nefrologia. VI Diretrizes Brasileiras de Hipertensão DBH VI. Rev Bras Hipertens. 2010;17(1):44-51.

4. Reis MG, Glashan RQ. Adultos hipertensos hospitalizados: percepção de gravidade da doença e da qualidade de vida. Rev. Latino-Am. Enfermagem. 2001;9(3):51-7.
5. Li W, Liu L, Puente JG, Li Y, Jiang X, Jin S, et al. Hypertension and health related quality of life: an epidemiological study in patients attending hospital clinics in China. J Hypertens. 2005;23(9):1667-76.

6. Erickson SR, Williams BC, Gruppen LD. Relationship Between Symptoms and Health-Related Quality of Life in Patients Treated for Hypertension. Pharmacotherapy. 2004; 24(3):344-50.

7. Banegas JR, López-Garcia E, Graciani A, GuallarCastillón, Gutierrez-Frisac JL, Alonso J, et al. Relationship between obesity, hypertension, and diabetes and healthrelated quality of life among the ederly. Eur Cardiovasc Prev Rehabil. 2007;14:456-62.

8. Kitzman DW, Little WC, Brubaker PH, Anderson RT, Hundley WG, Marburger CT, et al. Pathophysiological characterization of isolated diastolic heart failure in comparison to systolic heart failure. JAMA. 2002;288:2144-50.

9. Bulpitt $\mathrm{CJ}$, Fletcher AE. The measurement of quality of life in hypertensive patients: a practical approach. $\mathrm{Br}$ J Pharmac. 1990;30:353-64.

10. Roca-Cusachs A, Ametlla J, Calero S, Comas O, Fernández $M$, Lospaus $R$, et al. Calidad de vida en la hipertensión arterial. Med Clin (Barc). 1992;98:486-90. 11. Dalfó BA, Badia LX, Roca-Cusachs CA. Cuestionario de calidad de vida en hipertensión arterial (CHAL). Atención Primaria. 2002;29(2):116-21.

12. Youssef RM, Moubarak II, Kamel MI. Factors affecting the quality of life of hypertensive patients. East Mediterr Health J. 2005;11:109-18.

13. Gusmão JL, Mion D Jr., Pierin AMG. Avaliação da qualidade de vida do paciente hipertenso: proposta de um instrumento. Hipertensão. 2005;8(1):22-9.

14. Schulz RB, Rossignoli $P$, Correr $C$ J, Férnadez-Llimós $F$, Toni PM. Validação do mini-questionário de qualidade de vida em hipertensão arterial (MINICHAL) para o português (Brasil). Arq Bras Cardiol. 2008;90(2):139-44.

15. Ciconelli RM, Ferraz MB, Santos W, Meinão I, Quaresma MR. Tradução para a língua portuguesa e validação do questionário genérico de avaliação de qualidade de vida SF-36 (Brasil SF-36). Rev Bras Reumatol. 1999;39(3):143-50.

16. Carrara D. Avaliação prospectiva da qualidade de vida em pacientes com miocardiopatia dilatada submetidos à ventriculectomia parcial esquerda [Tese Doutorado] São Paulo (SP): Faculdade de Medicina da Universidade de São Paulo; 2001.

17. Rector TS, Kubo SH, Cohn J. Patient's selfassessment of their congestive heart failure. Part 2: Content, reliability an validity of a new measure. The Minnesota Living with Heart Failure Questionnaire. Heart Fail. 1987;3:198-209. 
18. Badia X, Roca-Cusachs A, Dalfó A, Gascón G, Abellán J, Lhos R, et al. Validation of short form of the Spanish hypertension quality of life questionnaire (MINICHAL). Clin Therap. 2002;24(12):2137-214.

19. Bennett SJ, Oldridge NB, Eckert GJ, Embree JL, Bowning $\mathrm{S}$, Hou $\mathrm{N}$, et al. Discriminant properties of commonly used quality of life measures in heart failure. Qual Life Res. 2002; 11:349-59.

20. McHorney CA, Ware JE, Lu JFR, Sherbourne CD. The MOS 36-item short-form health survey (SF-36): III. Tests of data quality, scaling assumptions and reliability across diverse patient groups. Med Care. 1994;32:40-66.

21. Scientific Advisory Committee of the Medical Outcomes Trust. Assessing health status and quality-oflife instruments: attributes and review criteria. Qual Life Res. 2002;11(3):193-205.

22. Streiner DL, Norman GR. Health Measurement Scales - A Practical Guide to Their Development and Use. $2^{\mathrm{a}}$ ed. Oxford: Oxford University Press; 2003.

23. Ajzen I, Fishbein M. Understanding attitudes and predicting social behavior. New Jersey: Prentice-Hall; 1980.

24. Nakajima KM, Rodrigues RCM, Gallani MCBJ, Alexandre NMC, Oldridge N. Psychometric properties of MacNew Heart Disease Health-related Quality of Life Questionnaire: brazilian version. JAN. 2009;65(5):1084-94.

25. Liang $\mathrm{MH}$. Longitudinal construct validity: Establishment of clinical meaning in patient evaluative instruments. Med Care. 2000; 38(Suppl 2):2-84-2-90. 26. Melchiors AC, Correr CJ, Pontarolo R, Santos FOS, Souza RAP. Qualidade de vida em pacientes hipertensos e validade concorrente do MINICHAL-Brasil. Arq Bras Cardiol. 2010; 94:(3):357-64. 